\title{
In situ preparation of poly(L-lactic acid-co-glycolic acid)/hydroxyapatite composites as artificial bone materials
}

\author{
Yuko Takeoka $^{1}$, Miki Hayashi ${ }^{1}$, Nami Sugiyama ${ }^{1}$, Masahiro Yoshizawa-Fujita ${ }^{1}$, Mamoru Aizawa $^{2}$ and \\ Masahiro Rikukawa ${ }^{1}$
}

Poly(L-lactic acid-co-glycolic acid)/hydroxyapatite (PLGA/HAp) composites were fabricated by the in situ polymerization of L-lactide and glycolide in porous HAp disks, using lipase MM, derived from Mucor miehei, as a catalyst. Various PLGA/HAp composites were obtained by changing the feed ratio of L-lactide and glycolide. The fourier transform infrared spectroscopy, scanning electron microscopy and porosity measurements showed that the porous HAp was completely filled with PLGA after polymerization at $100{ }^{\circ} \mathrm{C}$ for 9 days. Lactyl unit fractions $\left(F_{\mathrm{L}}\right)$ of obtained PLGA calculated from the ${ }^{1} \mathrm{H}$ nuclear magnetic resonance were consistent with the feed fraction of L-lactide $\left(f_{L}\right)$. The PGA/HAp, PLGA20/HAp, PLGA50/HAp, PLGA80/HAp and PLLA/HAp composites showed maximum bending strengths of $91.1 \mathrm{MPa}, 78.8 \mathrm{MPa}, 73.4 \mathrm{MPa}, 54.3 \mathrm{MPa}$ and $67.0 \mathrm{MPa}$, respectively. These values were 4.7-2.8 times greater than that of the untreated porous HAp disks and were suitable for artificial bone materials. The cell adhesion and proliferation properties of these materials with osteoblast-like MC3T3-E1 cells suggest that these PLGA/HAp composites have suitably bioactive surfaces. The PLGA/HAp composites showed higher alkaline phosphatase activity after cultivation of rat bone marrow stromal cells. Polymer Journal (2015) 47, 164-170; doi:10.1038/pj.2014.121; published online 17 December 2014

\section{INTRODUCTION}

Over the past few decades, there has been a growing need for artificial bone materials as a result of the increasing incidence of various bone diseases. Calcium phosphate ceramics such as hydroxyapatite (HAp) have been employed extensively for this purpose because they may be used as bioactive implants during human bone surgery owing to their similarity to bone mineral components. ${ }^{1-3}$ However, pure HAp bioceramics are only suitable for non-load-bearing applications because HAp is fragile and has low mechanical strength and poor fatigue resistance. Thus, researchers are actively seeking materials with mechanical properties that allow their use in load-bearing applications.

Recently, numerous investigations have been carried out concerning the hybridization of HAp with polymeric materials such as polyethylene, ${ }^{4}$ polymethacrylate ${ }^{5}$ and poly(lactic acid). ${ }^{6}$ Among these materials, biodegradable polymers are frequently used in combination with HAp because they have excellent biocompatibility. Research using the biodegradable polymer poly(L-lactic acid; PLLA) has been especially emphasized because PLLAs degrade into nontoxic chemical compounds at a controlled rate in vivo. PLLAs have already reached an advanced stage of utilization where they have been employed for the use as surgical implants, such as for the fixation of fractures and bone plates and as sutures. ${ }^{7-10}$ Most of the reported PLLA/HAp hybrid materials have been composites fabricated by dispersing HAp fibers or particles within a PLLA matrix. However, where researchers have attempted to increase the HAp content, the resulting composites did not have sufficient mechanical properties for artificial bone applications. For this reason, finding a suitable hybridization method for PLLA and HAp is critical in order to allow the fabrication of suitable artificial bone materials, because the ratio of these two component materials affects not only the mechanical properties but also the osteoconductivity and biocompatibility of the resulting hybrid. ${ }^{11,12}$

On the basis of the earlier work, we have succeeded in fabricating PLLA/HAp composites via the in situ polymerization of L-lactide within porous HAp disks without using any catalyst. ${ }^{13}$ These porous disks were fabricated by sintering calcium-phosphate fibers with longaxis dimensions ranging from 60 to $100 \mu \mathrm{m}$ creating continuous open pores, ${ }^{14}$ and thus providing sufficient space for the in situ polymerization. The in situ polymerization of L-lactide within such HAp disks containing continuous open pores enabled the hybridization of organic and inorganic materials in one synthetic process. Other groups have also reported varying methods of in situ polymerization, such as the preparation of PDLLA/calcium phosphate with tin(II) chloride and PLLA/inorganic mammalian bone without the use of catalyst. ${ }^{15,16}$ However, these prior methods still have unresolved issues related to achieving suitable mechanical properties, sufficient PLLA molecular weights and adequate biocompatibility. To overcome these problems, we combined our in situ polymerization with enzymatic 
catalysis to obtain PLLA/HAp composites with both superior mechanical properties and biocompatibility. ${ }^{17}$

Copolymers containing PLLA components have attracted much attention for the possible use in biomedical materials owing to their biodegradability and biocompatibility. ${ }^{18,19}$ Among the PLLA copolymers that have been extensively studied, poly(lactic acid-co-glycolic acid) (PLGA) is of great interest owing to its tunable physical and biological properties. ${ }^{20}$ The introduction of the hydrophilic poly(glycolic acid) (PGA) segment into the hydrophobic PLLA segments can lead to valuable copolymers with controlled hydrophilicity and degradability. ${ }^{21}$ Copolymers that are amphiphilic in nature can meet different purposes such as tissue engineering devices and drug delivery matrices. Here, we prepared a PLGA/HAp composite by using the in situ enzymatic polymerization of L-lactide and glycolide with respect to tuning the mechanical properties and biodegradability for the preparation of tailormade biomaterials. In addition, the mechanical properties and cell adhesion and proliferation properties of PLGA/HAp composites fabricated by this in situ polymerization process were evaluated.

\section{EXPERIMENTAL PROCEDURE}

\section{Materials}

L-lactide and glycolide were purchased from Tokyo Chemical Industry Co. Ltd (Tokyo, Japan) and Wako Pure Chemicals Co. Ltd (Tokyo, Japan), respectively. These monomers were recrystallized from distilled ethyl acetate. 1,1,1,3,3,3Hexafluoro-2-propanol (HFIP), lipase MM derived from the mold Mucor miehei, calcium nitrate tetrahydrate $\left(\mathrm{Ca}\left(\mathrm{NO}_{3}\right)_{2} \cdot 4 \mathrm{H}_{2} \mathrm{O}\right)$, diammonium hydrogen phosphate $\left(\left(\mathrm{NH}_{4}\right)_{2} \mathrm{HPO}_{4}\right)$, urea $\left(\left(\mathrm{NH}_{2}\right)_{2} \mathrm{CO}\right)$ and nitric acid purchased from Wako Pure Chemicals Co., Ltd were used as received. Pure HAp nanoparticles, HAp-100, used for the preparation of dense HAp pellets, were purchased from Taihei Chemical Industrial Co., Ltd (Osaka, Japan).

\section{Preparation of porous HAp pellets}

Fibrous HAp pellets with a $\mathrm{Ca} / \mathrm{P}$ ratio of 1.67 were synthesized from a reaction by precipitation method ${ }^{22}$ in aqueous solution containing $0.167 \mathrm{M} \mathrm{Ca}\left(\mathrm{NO}_{3}\right)_{2}$, $0.100 \mathrm{M}\left(\mathrm{NH}_{4}\right)_{2} \mathrm{HPO}_{4}, 0.500 \mathrm{M}\left(\mathrm{NH}_{2}\right)_{2} \mathrm{CO}$ and $0.100 \mathrm{M} \mathrm{HNO}_{3}$. Fibrous HAp was uniaxially compressed into molds at $30 \mathrm{MPa}$ and sintered at $1200^{\circ} \mathrm{C}$ for $5 \mathrm{~h}$ using an electric furnace KBF314N (Koyo Thermo Systems Co., Ltd, Nara, Japan). The porosity of the obtained porous HAp pellets ( $p$-HAp, diameter: $20 \mathrm{~mm}$, thickness: $2.0 \mathrm{~mm}$ ) was $\sim 40 \%$, which was calculated by using theoretical density of HAp $\left(3.16 \mathrm{~g} \mathrm{~cm}^{-3}\right)$.

\section{Fabrication of PLGA/HAp composites}

A $p$-HAp pellet was immersed in a mixture of L-lactide and glycolide with $2 \mathrm{wt}$. $\%$ lipase $\mathrm{MM}$, which was melted at $100^{\circ} \mathrm{C}$, and the mixture was freeze-thaw degassed three times in order to fill up the pores of $p$-HAp with L-lactide and glycolide before polymerization. The feed molar contents of L-lactide $\left(f_{\mathrm{L}}\right)$ were 0, 20, 50, 80 and 100 to obtain PGA/HAp, PLGA/HAp and PLLA/HAp. In situ polymerization was carried out by heating the HAp filled with monomers at $10{ }^{\circ} \mathrm{C}$ for 9 days under a $\mathrm{N}_{2}$ atmosphere. After the polymerization, the surface of the composites was polished and washed by ultrasonication with ethanol.

\section{Characterization of PLGA/HAp composites}

To characterize polymers obtained in the $p$-HAp, the polymers were eluted from the crushed composites using good solvents as eluents. For eluents, dimethylformamide was used for PLGA/HAp, whereas 1,1,1,3,3,3-Hexafluoro2-propanol and chloroform were used for PGA/HAp and PLLA/HAp, respectively. After extraction from the composites, the polymers were collected by reprecipitation. ${ }^{1} \mathrm{H}$ and ${ }^{13} \mathrm{C}$ nuclear magnetic resonance spectra were collected using JEOL Lambda 500 and 300 spectrometers (Tokyo, Japan). The molecular weights of the PLLAs were determined by gel permeation chromatography using a Shimadzu (Kyoto, Japan) LC-10AD system equipped with two Shodex KF806, Showa Denko (Tokyo, Japan) columns at $40^{\circ} \mathrm{C}$. Dimethylformamide for PLGA/HAp and tetrahydrofuran for PLLA/HAp were used as the eluents.
Fourier transform infrared spectra of the composites were measured using the attenuated total reflection attachment on a Nicolet Magna 750 spectrometer (Thermo Electron Co., Yokohama, Japan). Scanning electron microscopy (SEM) was carried out using a Hitachi S-4500 (Tokyo, Japan) at an accelerating voltage of $10-20 \mathrm{keV}$ and a magnification of $\times 5000$. Three-point bending tests to obtain the bending strength and elastic modulus were carried out using an A\&D TENSILON autograph RTG-1210 at a cross-head speed of $0.5 \mathrm{~mm} \mathrm{~min}^{-1}$ and a specimen size of $2.5 \mathrm{~mm}$ width and $2 \mathrm{~mm}$ height. The fracture toughness of the PLGA/HAp composites was determined by the single-edge notched beam method. ${ }^{23}$ Test samples were placed on a three-point bending apparatus with a support span of $10 \mathrm{~mm}$. Differential scanning calorimetry (DSC) measurements were conducted from -130 to $230^{\circ} \mathrm{C}$ using DSC6200 (Seiko Instruments Co., Ltd, Chiba, Japan) with a scanning rate of $10^{\circ} \mathrm{C} \mathrm{min}^{-1}$ under $\mathrm{N}_{2}$ flow. The crystallinities $\left(\chi_{\mathrm{c}}\right)$ of polymers in the composites were evaluated according to Equation 1.

$$
\chi_{\mathrm{c}}=\frac{\Delta H_{\mathrm{m}}}{\Delta H_{\mathrm{m}}(100 \%)} \times 100
$$

$\Delta H_{\mathrm{m}}$ : enthalpy of melting determined by DSC

$\Delta H_{\mathrm{m}}(100 \%)$ : enthalpy of melting of polymers whose $\chi_{\mathrm{c}}=100 \%$.

$\Delta H \mathrm{~m}(100 \%)$ for PGA is $183 \mathrm{Jg}^{-1}$ and $\Delta H_{\mathrm{m}}(100 \%)$ for PLLA is $93 \mathrm{~J} \mathrm{~g}^{-124,25}$

$C_{\text {PLLA }}$ : content of PLLA in the composite (\%)

$C_{\mathrm{PGA}}$ : content of PGA in the composite (\%)

\section{Evaluation of cell adhesion and proliferation}

For cell cultivation, pellets with a diameter of $16 \mathrm{~mm}$ were used. The biocompatibility of the composites was evaluated by determining cell adhesion and proliferation toward osteoblast-like MC3T3-E1 cells. The composites were sterilized for $22 \mathrm{~h}$ with ethylene oxide gas (Elk, SA-160) at $40^{\circ} \mathrm{C}$. The composites were then placed in a 24-well tissue culture polystyrene plate, washed three times with phosphate-buffered saline and immersed in $\alpha$-minimum essential medium $(\alpha-M E M$, GIBCO, Tokyo, Japan) for $24 \mathrm{~h}$ before cell seeding. MC3T3-E1 cells were cultured for 7 days in $\alpha$-MEM supplemented with $10 \%$ fetal bovine serum (GIBCO) at $37^{\circ} \mathrm{C}$ in a humidified atmosphere containing $5 \% \mathrm{CO}_{2}$. The culture medium in the well was changed every other day. Bare polystyrene well plates and dense HAp pellets (sintered pure HAp; Taihei Chemical Industrial Co., Ltd) were used as the controls. After trypsin treatments, the surrounding tissues were manually removed and the numbers of attached cells were counted. The effect of glycolic acid and L-lactic acid on the cell adhesion was investigated using $\alpha$-MEM containing various amounts of glycolic acid and L-lactic acid. The $\mathrm{pH}$ values of the medium were controlled from 2.61 to 8.20 for glycolic acid-containing medium and 4.03 to 8.25 for L-lactic acid-containing medium. By using bone marrow stromal cells (RBMCs), the differentiation to bone on the composites was investigated. 4-week-old male Wistar rats $\mathrm{S} / \mathrm{T}$ clean std. were euthanized by using diethyl ether. The bone marrow was collected from the femoral and tibial bones with a 21-gauge needle under sterile conditions and suspended in $10 \mathrm{ml}$ of $\alpha$-MEM containing penicillin (Wako Pure Chemical), streptomycin (SigmaAldrich, Tokyo, Japan) and amphotericin B (Sigma-Aldrich). The bone marrow cell pellet was washed three times in $\alpha$-MEM with antibacterial and antifungal agents. Each mixture was centrifuged at 1000 r.p.m. for $5 \mathrm{~min}$ and then resuspended in $\alpha$-MEM containing $10 \%$ fetal bovine serum, $100 \mu \mathrm{g} \mathrm{ml}^{-1}$ penicillin, $100 \mu \mathrm{g} \mathrm{ml}^{-1}$ streptomycin and $2.5 \mu \mathrm{g} \mathrm{m}^{-1}$ amphotericin B. The cells were then seeded to a $10-\mathrm{mm}$ diameter cell culture well and incubated at $37{ }^{\circ} \mathrm{C}$ in a humidified atmosphere of $5 \% \mathrm{CO}_{2}$ and $95 \%$ air. Non-adherent cells were removed by changing the medium after $24 \mathrm{~h}$. The culture medium was changed every day to remove the hematocytes. The alkali phosphatase (ALP) activity was measured using a kit from Kainos Co., Ltd (Tokyo, Japan).

\section{RESULTS AND DISCUSSION}

In situ polymerization of L-lactide and glycolide with lipase MM The total porosity of the prepared $p$-HAp disks, calculated from relative density values of Hap, was $\sim 40-42 \%$. As shown in Figure 1a, a porous morphology was observed with microscale holes on cross sections of $p$-HAp. Both scanning electron microscopy and mercury porosimetry measurements suggested that most of these pores are 

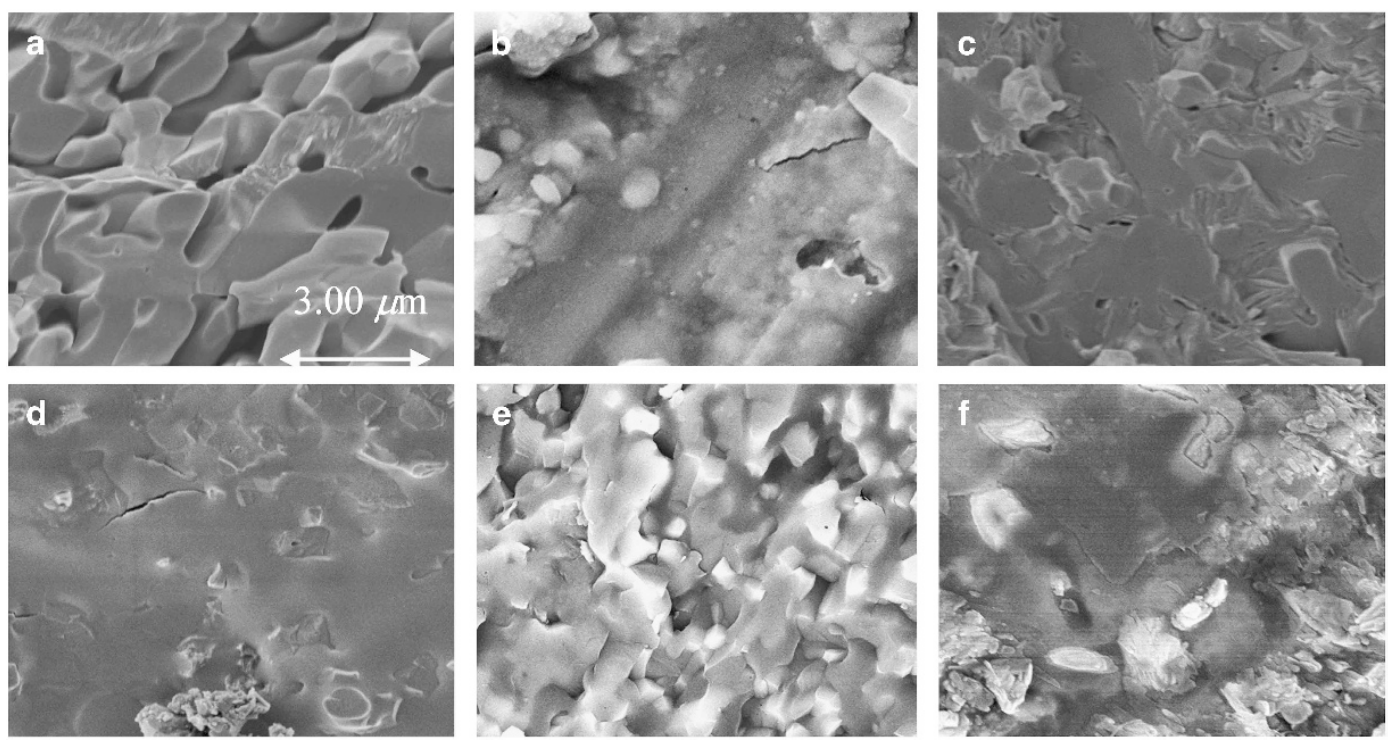

Figure 1 Cross-sectional scanning electron microscopy images of (a) p-hydroxyapatit (HAp), (b) poly(glycolic acid)/HAp, (c) poly(L-lactic acid-co-glycolic acid) (PLGA)20/HAp, (d) PLGA50/HAp, (e) PLGA80/HAp and (f) poly(L-lactic acid)/HAp composites polymerized at $100{ }^{\circ} \mathrm{C}$ for 9 days.<smiles>CC1OC(=O)C(C)OC1=O</smiles>

L-lactide<smiles>O=C1COC(=O)CO1</smiles>

glycolide

\section{$2 \mathrm{wt} \%$ Lipase MM}<smiles>CC(C)OCC(=O)C(C)(C)OC(C)C(=O)O</smiles>

Poly(lactic acid-co-glycolic acid)

Scheme 1 Synthesis of poly(lactic acid-co-glycolic acid (PLGA).

continuous open pores, ${ }^{26}$ into which lipase and monomers can be introduced. ${ }^{14,27}$ We previously attempted the use of the solutioninfiltration method to create PLLA/HAp composites. However, $~ 80 \%$ of the total pore volume remained unfilled in the PLLA/HAp composites produced, even when using $50 \mathrm{wt} . \%$ PLLA solution. ${ }^{17}$ As similar phenomena were observed for the preparation of PLGA/ HAp composites, we adopted in situ polymerization of monomers in the pores of $p$-HAp. In situ polymerization of L-lactide and glycolide was conducted by heating $p$-HAp pellets filled with the mixture of L-lactide and glycolide with $2 \mathrm{wt} \%$ lipase $M M$ as a catalyst as shown in Scheme 1. Feed molar fraction of L-lactide $\left(f_{\mathrm{L}}\right)$ was controlled at 20 , 50 and 80 to obtain PLGA $\left(f_{\mathrm{L}}\right) / \mathrm{HAp}$ composites. PGA/HAp and PLLA/HAp composites were also prepared by similar conditions from p-HAp filled with glycolide and L-lactide, respectively. Enzymecatalyzed polymerization has several desirable characteristics, including enantioselectivity, high catalytic activity, lack of undesirable side reactions and mild reaction conditions. ${ }^{28,29}$ It is also well suited to the fabrication of biomaterials for practical applications owing to the low risk of toxic chemical residues.

Fabrication of PLGA/HAp composites was confirmed by scanning electron microscopy images and fourier transform infrared spectra. Figures $1 \mathrm{~b}-\mathrm{f}$ shows the cross-sectional scanning electron microscopy images of PGA/HAp, PLGA/HAp and PLLA/HAp composites prepared by in situ polymerization at $100{ }^{\circ} \mathrm{C}$ for 9 days. Compared with the porous morphology observed for $p$-HAp, the cross sections of the PGA/HAp, PLGA/HAp and PLLA/HAp composites were relatively smooth, showing that the pores of HAp pellets were completely filled with polymers after in situ polymerization. Figure 2 shows the attenuated total reflection-infrared spectra of dense HAp pellet and polymer/HAp composites polymerized at $100^{\circ} \mathrm{C}$ for 9 days. The spectrum of the HAp disk shows a characteristic absorption band at $1100-1000 \mathrm{~cm}^{-1}$ assigned to the $\mathrm{PO}_{4}{ }^{3-}$ groups, and the peak at $\sim 3500 \mathrm{~cm}^{-1}$ assigned to the $\mathrm{OH}^{-}$was detected. The former band is due to the stretching vibration of surface $\mathrm{P}-\mathrm{OH}$ groups generated by the protonation of surface $\mathrm{PO}_{4}{ }^{3-}$ ions that maintain the surface charge balance of HAp and the latter band is attributed to the stretching vibration of $\mathrm{OH}^{-}$ions in the HAp lattice, according to Tanaka et al..$^{30}$

The fourier transform infrared spectra of PLGA/HAp composites showed some new absorption bands that were not observed in those of the HAp pellet. Newly observed bands at 3000-2840, 1768 and 1440 $\mathrm{cm}^{-1}$ were attributed to $\mathrm{C}-\mathrm{H}$ stretching, $\mathrm{C}=\mathrm{O}$ stretching and $\mathrm{C}-\mathrm{H}$ deformation vibrations, respectively. These results demonstrated that PLGA was hybridized with HAp. Similar results were observed for PGA/HAp and PLLA/HAp composites. Figure 3 shows the residual porosity of the composites, determined by a pycnometer method, as a function of in situ polymerization time. The porosity of the composites gradually decreased against polymerization time and reached nearly zero on the ninth day, indicating that the pores of $p$-HAp were completely filled with polymers. The porosities of PGA/HAp and PLGA20/Hap, prepared by low $f_{\mathrm{L}}$ conditions, decreased faster than did those of PLGA50/HAp, PLGA80/HAp and PLLA/HAp composites, prepared by high $f_{\mathrm{L}}$ conditions. This result shows that the polymerization of glycolide proceeds faster than that of L-lactide in $p$-HAp. 


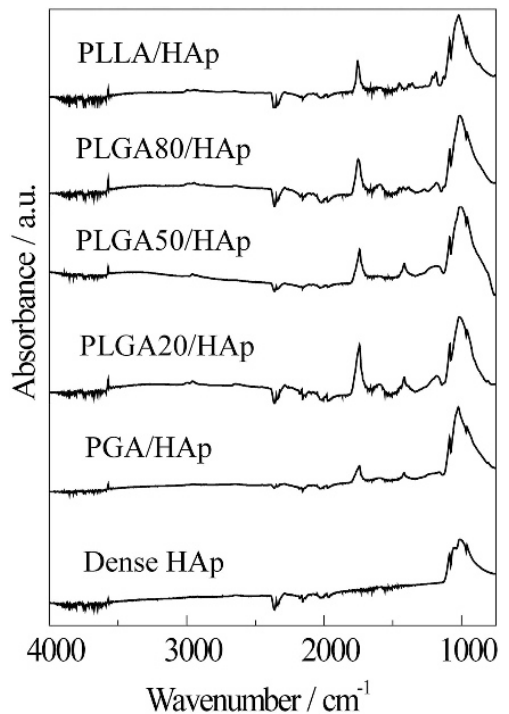

Figure 2 Attenuated total reflection-infrared spectra of the polymer/HAp composites and dense HAp.

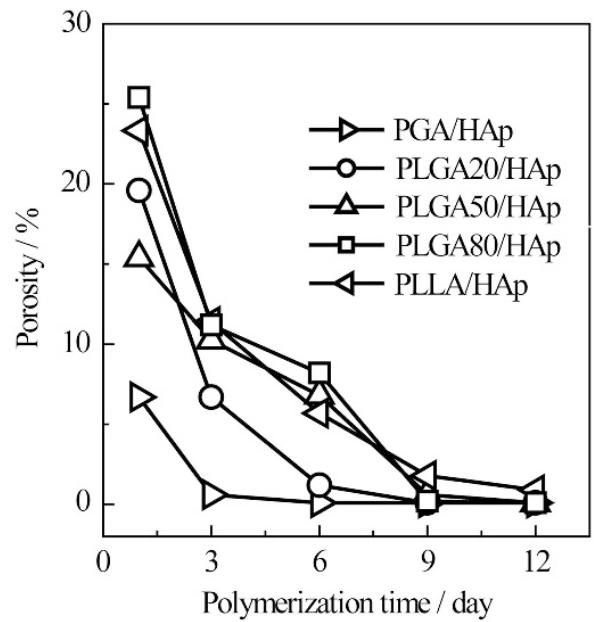

Figure 3 Porosity of the composites prepared at $100^{\circ} \mathrm{C}$ as a function of polymerization time.

To characterize the polymers obtained in $p$-HAp, the polymers were eluted from the crushed composites using solvents as eluents. For eluents, dimethylformamide was used for PLGA/HAp, whereas 1,1,1,3,3,3-Hexafluoro-2-propanol and tetrahydrofuran were used for PGA/HAp and PLLA/HAp, respectively. The ${ }^{1} \mathrm{H}$ nuclear magnetic resonance spectrum of PGA showed a chemical shift at 4.9 p.p.m., which was assigned to methylene protons, and PLLA showed methine protons at 5.2 p.p.m. (Supplementary Figure S1). By comparing the integrated intensities of these signals, we could estimate the lactinyl unit fraction $\left(F_{\mathrm{L}}\right)$ of the obtained PLGA. Figure 4 shows the polymerization time dependence of $F_{\mathrm{L}}$ of PLGA polymerized in $p$-HAp using the mixture of L-lactide and glycolide with each feed L-lactide ratio $\left(f_{\mathrm{L}}\right)$. The $F_{\mathrm{L}}$ values of PLGA gradually increased with the increases in polymerization time. At shorter polymerization times, the $F_{\mathrm{L}}$ values were lower than those expected by the feed molar ratio $\left(f_{\mathrm{L}}\right)$ for all cases, suggesting that the ring-opening polymerization of glycolide proceeded faster than that of L-lactide. After the ninth day, the $F_{\mathrm{L}}$ values nearly reached the theoretical values. The weight-average

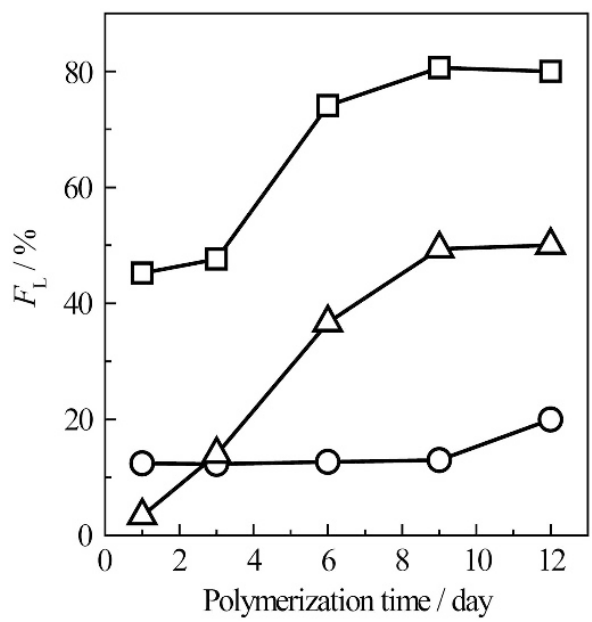

Figure $4 F_{\mathrm{L}}$ of poly(L-lactic acid-co-glycolic acid) ( $f_{\mathrm{L}}=20 \%$ (circle), $50 \%$ (triangle) and $80 \%$ (square)) polymerized at $100{ }^{\circ} \mathrm{C}$ in $p$-hydroxyapatit.

molecular weights $\left(M_{\mathrm{w}}\right)$ of PLGA polymerized in porous HAp using the mixture of L-lactide and glycolide with $f_{\mathrm{L}}=20,50$ and $80 \%$ were $2.5 \times 10^{3}-5.0 \times 10^{3}$ after 9 days of polymerization, and the polydispersity indexes were $<1.5$. The $M_{\mathrm{w}}$ values after 12 days of polymerization were comparable to those of 9 days of polymerization.

\section{Mechanical properties of PLGA/HAp composites}

The hybridization of HAp- and PLLA-based polymers has been anticipated to combine the superior mechanical properties and biodegradability of PLLA with the excellent osteoconductivity of calcium phosphates. ${ }^{6,31}$ The inorganic-organic composite strategy also allows the advantages of each material to offset the drawbacks of the other. The fragility of calcium phosphates is thus improved by the flexibility of the polymer, whereas the biocompatibility of the polymer is improved by the calcium phosphates. As an example, Verheyen et al..$^{32}$ have developed PLLA/HAp composites prepared by polymerizing the mixtures of HAp particles and L-lactide. The initial bending strengths of those composites were $\sim 70-90 \mathrm{MPa}$ and $50 \%$ of the bending strength was maintained 3 weeks after implantation. In addition, biological tests showed that these composites had greater bone contact than those made of unfilled PLLAs.

In our previous study, the PLLA/HAp composites were fabricated by the in situ polymerization of L-lactide in porous HAp without the use of catalysts. ${ }^{13}$ The bending strength and fracture toughness of these PLLA/HAp composites were $53.7 \mathrm{MPa}$ and $0.52 \mathrm{MPa} \mathrm{m}^{1 / 2}$, respectively. These values approached the mechanical properties of human cortical bones ${ }^{33,34}$ (a bending strength of 50-150 MPa and a fracture toughness of 2-12 $\mathrm{MPa} \mathrm{m}^{1 / 2}$ ); however, the fracture toughness should be increased for the application to artificial bone materials. In this study, the effect of copolymerization with PGA on the mechanical properties was investigated. The evaluation of the mechanical properties of artificial bone materials has been reported using compression tests, three- or four-point bending tests, ${ }^{33,35,36}$ and tensile tests. ${ }^{37}$ In this study, we used bending strength, as measured by three-point bending tests, to evaluate the mechanical properties of the PLGA/HAp composites. The optical micrograph observation shows that PLLAs of similar molecular weight formed spherical crystallites above $110^{\circ} \mathrm{C}$. On the basis of the results, all the composites were annealed at $110^{\circ} \mathrm{C}$ for $24 \mathrm{~h}$ under $\mathrm{N}_{2}$ flow before mechanical measurements.

The polymerization time dependence of bending strength of PGA/ HAp, PLGA/HAp and PLLA/HAp composites are shown in Figure 5. 


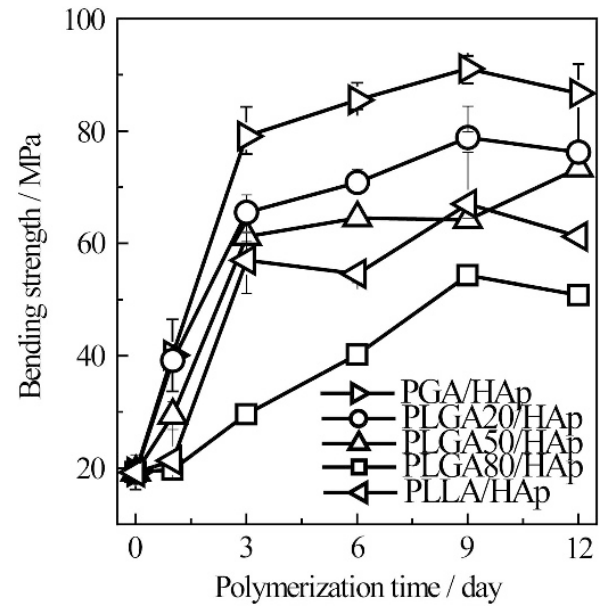

Figure 5 Bending strength of the composites polymerized at $100^{\circ} \mathrm{C}$ as a function of polymerization time $(n=4)$.

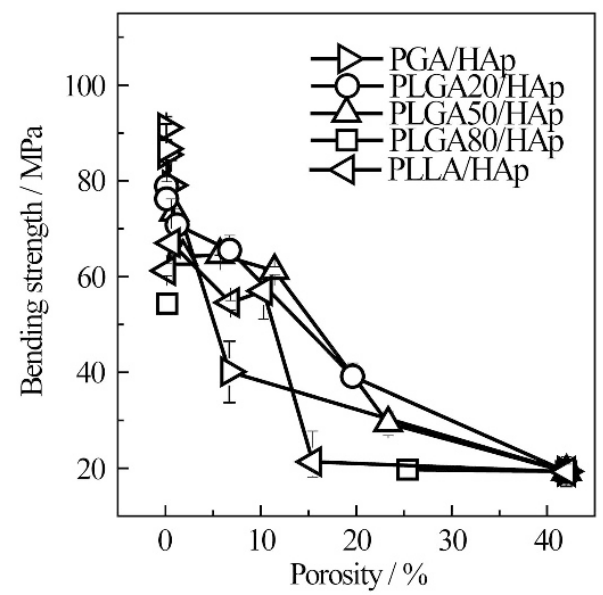

Figure 6 Bending strength of the composites as a function of porosity $(n=4)$.

The bending strength of the composites increased with increasing polymerization time. Maximum bending strengths were obtained after 9 days of polymerization, except for PLGA50/HAp (12 day). Although the molecular weights of the polymers in the composites were not very dependent on the polymerization time after 6 days, the increase of bending strength against the polymerization time is related to the porosity of the composites. Figure 6 shows the relationship between the bending strength and porosity of the composites. As the porosity decreased from the initial values $(42 \%)$ to $0 \%$, the bending strength tended to increase to the maximum values of each of the composites. These results showed that the residual porosity of the composites deeply influenced the mechanical properties of the composites. PGA/ HAp, PLGA20/HAp, PLGA50/HAp, PLGA80/HAp and PLLA/HAp composites showed maximum bending strengths of $91.1 \mathrm{MPa}, 78.8$ $\mathrm{MPa}, 73.4 \mathrm{MPa}, 54.3 \mathrm{MPa}$ and $67.0 \mathrm{MPa}$, respectively. These values were 4.7-2.8 times greater than that of the untreated porous HAp disks. Figure 7 shows the $F_{\mathrm{L}}$ dependence of maximum bending strength and fracture toughness of the composites. Except for $F_{\mathrm{L}}=80 \%$, the bending strength and fracture toughness decreased against the increase of $F_{\mathrm{L}}$. PGA/HAp, PLGA20/HAp, PLGA50/HAp, PLGA80/HAp and PLLA/HAp composites showed fracture toughnesses of $1.3 \mathrm{MPa} \mathrm{m}^{1 / 2}, 1.2 \mathrm{MPa} \mathrm{m}^{1 / 2}, 1.1 \mathrm{MPa} \mathrm{m}^{1 / 2}, 0.57 \mathrm{MPa} \mathrm{m}^{1 / 2}$

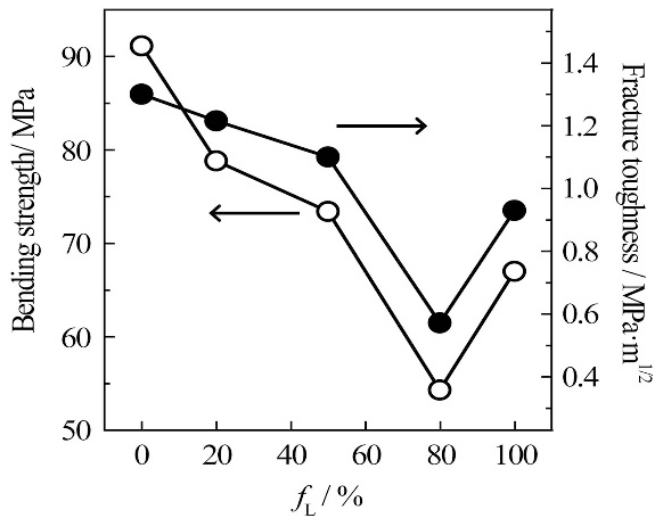

Figure 7 Bending strength (open plot) and fracture toughness (closed plot) of the composites as a function of $F_{\mathrm{L}}$ in the composites $(n=4)$.

and $0.93 \mathrm{MPam}^{1 / 2}$, respectively. The fracture toughness of the composites approached the mechanical properties values reported for cortical bones, ${ }^{33,34}$ and the bending strengths were also sufficient for the application to artificial bone materials. These mechanical properties are superior to those reported for PLLA/HAp.

PLGA80/HAp composites showed lower mechanical properties than expected for the content of PGA and PLLA. To investigate the reason, DSC measurements were conducted for the composites. Table 1 shows the $T_{\mathrm{m}}$ values and fusion enthalpy $\left(\Delta H_{\mathrm{m}}\right)$ of the composites observed by DSC. Although other composites showed an endothermic peak owing to the crystal fusion at melting point $\left(T_{\mathrm{m}}\right)$, PLGA80/HAp showed no peak, suggesting that PLGA80 is an amorphous polymer. A higher $T_{\mathrm{m}}$ and a larger $\Delta H_{\mathrm{m}}$ were observed for GA-rich PLGA/HAp. These results showed that the crystallinity of the PLGA reflected the mechanical properties of the composites.

\section{Evaluation of cell adhesion and proliferation}

The biocompatibility of the composites was investigated using MC3T3-E1 cells. The adhesion ratio $5 \mathrm{~h}$ after cell seeding and the doubling time of the MC3T3-E1 cells on the surface of dense HAp and the composites are shown in Table 1. While the adhesion ratios of the PLGA20/HAp, PLGA50/HAp, PLGA80/HAp and PLLA/HAp composites were $~ 30-39 \%$ and were slightly lower than that of dense HAp $(45.8 \pm 12.8 \%)$, the doubling times were comparable to that of dense HAp $(23.6 \pm 5.3 \mathrm{~h})$. On the contrary, the PGA/HAp composite showed lower adhesion ratios of MC3T3-E1 cells and longer doubling time compared with HAp. By determining the $\mathrm{pH}$ change of medium after $5 \mathrm{~h}$ cultivation of MC3T3-E1 cells on the composites, a decrease of $\mathrm{pH}$ was apparently observed for PGA/HAp composites as shown in Table 1. This might be the elution of glycolic acid derived from the degradation of PGA. To confirm the effect of $\mathrm{pH}$ and the existence of glycolic acid, the cell adhesion and proliferation of MC3T3-E1 cells was measured using a medium containing glycolic acid and L-lactic acid. Figure 8 shows the adhesion ratio of MC3T3-E1 cells after $5 \mathrm{~h}$ of cultivation on a polystyrene dish using $\alpha-\operatorname{MEM}(+)$ containing glycolic acid and L-lactic acid. Adhesion ratios were apparently influenced by the $\mathrm{pH}$ and the existence of glycolic acid and L-lactic acid. This result showed that the low cell attachment of PGA/HAp was owing to the decrease of $\mathrm{pH}$ induced by the production of glycolic acid.

To investigate the potential of the composites to induce osteoblast gene expression, rat RBMCs were cultured on the composites at $37^{\circ} \mathrm{C}$ in $5 \% \mathrm{CO}_{2}$ in an $\alpha$-MEM for 35 days. Figure 9 shows the ALP activity per mass of DNA of RBMCs cultivated on the composites and dense HAp. ALP is a differentiation maker for osteoblast promotion. The 
Table $1 T_{\mathrm{m}}$ and results of MC3T3-E1 cell cultivation on PLGA/HAp composites

\begin{tabular}{|c|c|c|c|c|c|c|c|}
\hline $\mathrm{f}_{L} / \%$ & $\mathrm{~F}_{L} \%$ & $\mathrm{~T}_{m}{ }^{\mathrm{a}}{ }^{\circ} \mathrm{C}$ & $\Delta \mathrm{H}_{m} \mathrm{~b} / J g^{-1}$ & Crystallinity $/ \%$ & Adhesion ratiod $/ \%$ & Doubling time/h & $\mathrm{pH}$ after immersion in PBS \\
\hline 0 & 0 & 210.2 & 97.6 & 53 & $19.0 \pm 2.2$ & 39.9 & 3.59 \\
\hline 20 & 13 & 197.3 & 93.8 & 55 & $38.8 \pm 3.7$ & 24.9 & 6.42 \\
\hline 50 & 50 & 177.9 & 21.6 & 16 & $33.7 \pm 12.0$ & 23.9 & 4.24 \\
\hline 80 & 80 & - & - & 0 & $31.5 \pm 3.9$ & 24.6 & 7.07 \\
\hline 100 & 100 & 128.7 & 10.1 & 9.1 & $32.5 \pm 14.6$ & 22.6 & 6.72 \\
\hline
\end{tabular}

Abbreviation: DSC, differential scanning calorimetry; $\Delta H_{\mathrm{m}}$, enthalpy of melting; PLGA/HApPBS, phosphate-buffered saline; PLGA/HAp, Poly(L-lactic acid-co-glycolic acid)/hydroxyapatite; $T_{\mathrm{m}}$, melting point.

a Melting temperature determined by DSC. No $T_{\mathrm{m}}$ was observed for PLGA $\left(F_{\mathrm{L}}=80 \%\right)$

F Fusion enthalpy determined by DSC.

'Determined by Equation 1.

dAfter 5 h cultivation of MC3T3-E1.

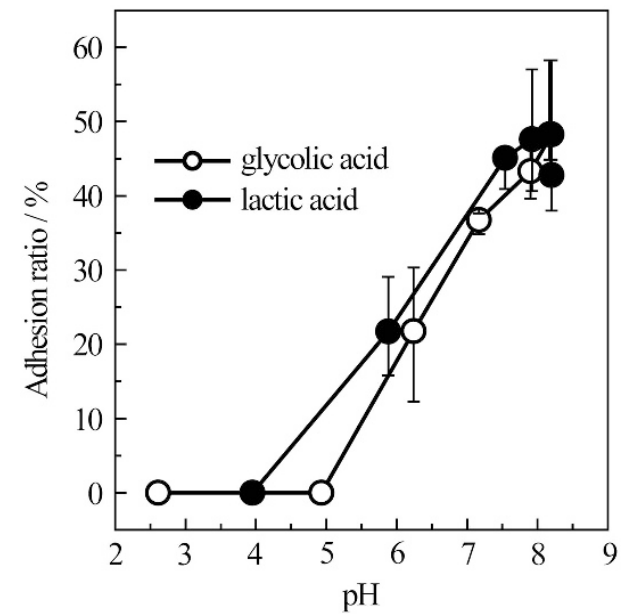

Figure 8 Adhesion ratio of MC3T3-E1 cells on polystyrene using $\alpha-M E M(+)$ containing glycolic acid or lactic acid.

DNA content was determined using Hoechst 33258 reagent (Dojindo Laboratories, Kumamoto, Japan). Here, DNA was derived from proliferated RBMCs; therefore, the DNA content in Figure 9 is proportional to the proliferated cell numbers. PGA/HAp and PLLA/ HAp showed ALP activity on the 14th day. After 21 days incubation of RBMCs, the composites exhibited higher levels of ALP expression compared with dense HAp ceramic. ALP activity was affected by PLLA composition and biodegradability of the polymers in the composites. The ALP activity of the PLLA/HAp composite was higher than that of other composites, showing that PLLA enhanced the differentiation of RBMCs. PGA/HAp and PLGA50/HAp composites showed higher ALP activity, which was estimated from the PLLA composition ratio. As shown in Table 1, the $\mathrm{pH}$ after immersion of PGA/HAp and PLGA50/ HAp in phosphate-buffered saline was lower than other composites, suggesting that the molecular weight decreased faster than other composites. As reported by Isama and Tsuchiya ${ }^{38}$ low molecular weight biodegradable polymers enhanced the differentiation of MC3T3-E1 cells. Similar phenomena might be observed in our case. Detailed analyses are now underway.

\section{CONCLUSIONS}

We examined the in situ polymerization of L-lactide and glycolide using lipase $M M$ in porous HAp to fabricate PLGA/HAp, PGA/HAp and PLLA/HAp composites. The pores of porous HAp were filled with polymers over 9 days of polymerization, and the mechanical properties of the obtained PLGA/HAp composites were controllable by changing the feed ratio of L-lactide and glycolide. The composites showed a

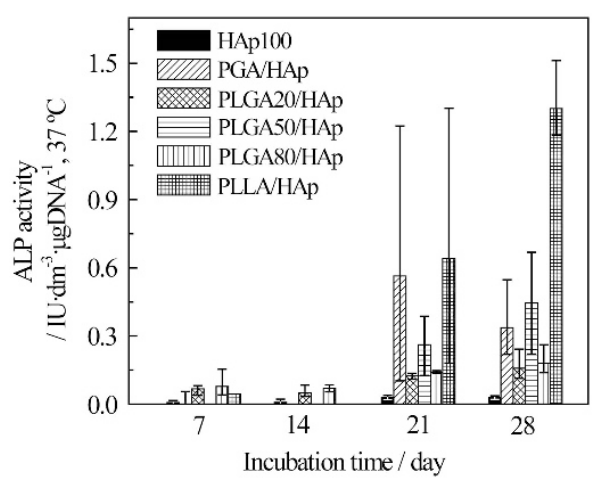

Figure 9 ALP activity per mass of DNA at $37^{\circ} \mathrm{C}$ of RBMC cultivated on the composites and HAp.

maximum bending strength up to $90-54 \mathrm{MPa}$ and fracture toughness of $1.3-0.57 \mathrm{MPa} \mathrm{m}^{1 / 2}$, both of which are close to the mechanical property values of cortical bones. The composites provide not only improved mechanical properties but also good biocompatibility, suggesting that these composites are potential candidates for bone tissue engineering. Further in vivo analyses are needed to assess the capacity of these composites for bone regeneration.

\section{ACKNOWLEDGEMENTS}

This work was partly supported by JSPS KAKENHI Grant-in-Aid for Scientific Research on Innovative Areas 'Fusion Materials'.

1 Bucholz, R. W., Carlton, A. \& Holmes, F. E. Hydroxyapatite and tricalcium phosphate bone graft substituents. Orthop. Clin. North Am. 18, 323-334 (1987).

2 van Blitterswijk, C. A., Grote, J. J., Kuijpers, W., Daems, W. T. \& de Groot, K. Macropore tissue ingrowth: a quantitave and qualitative study on hydroxyapatite. Biomaterials 7 , 137-143 (1986)

3 Suchanek, W. \& Yoshimura, M. Processing and properties of hydroxyapatite-based biomaterials for use as hard tissue replacement implants. J. Mater. Res. 13, 94-117 (1998).

4 Nazhat, S., Joseph, R., Wang, M., Smith, R., Tanner, K. \& Bonfield, W. Dynamic mechanical characterization of hydroxyapatite reinforced polyethylene: effect of particle size. J. Mater. Sci. Mater. Med. 11, 621-628 (2000).

5 Chu, K., Oshida, Y., Hancock, E., Kowolik, M., Barco, T. \& Zunt, S. Hydroxyapatite/PMMA composites as bone cements. Biomed. Mater. Eng. 14, 87-105 (2004).

6 Ishii, S., Tamura, J., Furukawa, T., Nakamura, T., Matsusue, Y., Shikinam, Y. \& Okuno, M. Long-term study of high-strength hydroxyapatite/poly(L-lactide) composite rods for the internal fixation of bone fractures: a 2-4 year follow-up study in rabbits. J. Biomed. Mater. Res. B Appl. Biomater. 66, 539-547 (2003).

7 Matsusue, Y., Hanafusa, S., Yamamuro, T., Shikinami, Y. \& Ikada, Y. Tissue reaction of bioabsorbable ultrahigh strength poly(L-lactide) rod. A long-term study in rabbits. Clin. Orthop. Relat. Res. 317, 246-253 (1995). 
8 Joukainen, A., Partio, E., Waris, P., Joukainen, J., Kröger, H., Törmälä, P. \& Rollanen, P. Bioabsorbable screw fixation for the treatment of ankle fractures. J. Orthop. Sci. 12, 28-34 (2007).

9 Backstrom, A., Raiha, J., Valimaa, T. \& Tulamo, R. Repair of radical fractures in toy breed dogs with self-reinforced biodegradabe bone plates, metal screws, and lightweight external coaptation. Vet. Surg. 34, 11-17 (2005).

10 Makela, P., Pohjonen, T., Tormala, P., Waris, T. \& Ashammakhi, N. Strength retention properties of self-reinforced polyL-lactide (SR-PLLA) sutures compared with polyglyconate (Maxon) and polydioxanone (PDS) sutures. An in vitro study. Biomaterials 23, 2587-2592 (2002).

11 Suriyan, R., Yupaporn, R., Wimonlak, S. \& Nitinat, S. Effects of mixing technique and filler content on physical properties of bovine bone-based CHA/PLA composites. J. Appl. Polym. Sci. 122, 2433-2441 (2011).

12 Aydin, E., Planell, J.A. \& Hasirci, V. Hydroxyapatite nanorod-reinforced biodegradable poly(L-lactic acid) composites for bone plate applications. J. Mater. Sci. Mater. Med. 22, 2413-2427 (2011).

13 Sugiyama, N., Kunibu, R., Yoshizawa-Fujita, M., Takeoka, Y., Aizawa, M. \& Rikukawa, M. Ring-opening bulk polymerization of L-lactide in porous hydroxyapatite. Chem. Lett. 36, 1476-1477 (2007).

14 Aizawa, M., Porter, A., Best, S. \& Bonfield, W. Ultrastructural observation of single-crystal apatite fibers. Biomaterials 26, 3427-3433 (2005).

15 Ehrenfried, L., Farrar, D. \& Cameron, R. Degradation properties of co-continuous calcium-phosphate-polyester composites. Biomacromolecules 10, 1976-1985 (2009).

16 Wiegand, T., Karr, J., Steinkruger, J., Hiebner, K., Simetich, B. \& Beatty, M. Recognition of anorganic mammalian bone by surface-initiated polymerization of L-lactide. Chem. Mater. 20, 5016-5022 (2008).

17 Sugiyama, N., Ohno, T., Kunibu, R., Aizawa, M., Takeoka, Y. \& Rikukawa, M. In situ preparation of poly(L-lactic acid)/hydroxyapatite composites as artificial bone materials. Kobunshi Ronbunshu 70, 185-192 (2013).

18 Griffith, L. G. Polymeric biomaterials. Acta. Mater. 48, 263-277 (2000).

19 Rashkov, I. \& Manolova, N. Synthesis, characterization, and hydrolytic degradation of PLA/PEO/PLA triblock copolymers with short poly(L-lactic acid) chains. Macromolecules 29, 50-56 (1996).

20 Jeong, B., Bae, Y. H. \& Kim, S. W. Thermoreversible gelation of PEG-PLGA-PEG triblock copolymer aqueous solutions. Macromolecules 32, 7064-7069 (1999).

21 Lee, J.-W. \& Gardella, J. A. In vitro hydrolytic surface degradation of poly(glycolic acid): Role of the surface segregated amorphous region in the induction period of bulk erosion. Macromolecules 34, 3928-3937 (2001).

22 Aizawa, M., Howell, F., Itatani, K., Yokogawa, Y., Nishizawa, K., Toriyama, M. \& Kameyama, T. Fabrication of porous ceramics with well-controlled open pores by sintering of fibrous hydroxyapatite particles. J. Ceram. Soc. Jpn. 108, 249-253 (2000).
23 Pearson, R. Toughening of Plastic. ACS Symposium Series 759, 1-12 (2000).

24 Standard specification for poly(glycolide) and poly(glycolide-co-lactide) resins for surgical implants with mole fractions greater than or equal to $70 \%$ glycolide. ASTM F2313-10 (2008)

25 Fischer, E. W., Sterzel, H. J. \& Wegner, G. Investigation of the structure of solution grown crystals of lactide copolymers by means of chemicals reactions. Kolloid-Z. $Z$. Polym. 251, 980-990 (1973).

26 Sugiyama, N., Yanagi, Y., Yoshizawa-Fujita, M., Aizawa, M., Takeoka, Y. \& Rikukawa, M. DNA-templated fabrication of biphasic calcium phosphate ceramics with a bimodal pore structure for tissue engineering. Chem. Lett. 42, 465-467 (2013).

27 Aizawa, M., Ito, M., Takeoka, Y., Rikukawa, M. \& Okada, I. Fabrication of porous teicalcium phosphate ceramics from calcium-phosphate fibers for a matrix of biodegradable ceramics/polymer hybrids. Phosphorus Res. Bull. 17, 209-210 (2004).

28 Matsumura, S. Enzyme-catalyzed synthesis and chemical recycling of polyesters. Macromol. Biosci. 2, 105-126 (2002).

29 Matsumura, S., Mabuchi, K. \& Toshima, K. Novel ring-opening polyerization of lactide by lipase. Macromol. Symp. 130, 285-304 (1998).

30 Tanaka, H., Chikazawa, M., Kandori, K. \& Ishikawa, T. Influence of thermal treatment on the structure of calcium hydroxyapatite. Phys. Chem. Chem. Phys. 2 2647-2650 (2000).

31 Hong, Z., Zhang, P., He, C., Qiu, X., Liu, A., Chen, L., Chen, X. \& Jing, X. Nano-composite of poly(L-lactide) and surface grafted hydroxyapatite: mechanical properties and biocompatibility. Biomaterials 26, 6296-6304 (2005).

32 Verheyen, C., de Wijn, J., Blitterswijk, C. V. \& de Groot, K. Evaluation of hydroxyapatite/ poly(L-lactide) composites: mechanical behavior. J. Biomed. Mater. Res. 26, 1277-1296 (1992).

33 Kokubo, T., Kim, H. \& Kawashita, M. Novel bioactive materials with different mechanical properties. Biomaterials 24, 2161-2175 (2003).

34 White A. \& Best S. Bone Repair Biomaterials (eds Planell J., Best S., Lacroix D. \& Merolli A.), 122-125 (CRC Press, London, UK, 2009)

35 Kannan, S., Lemos, A. \& Ferreira, J. Synthesis and mechanical performance of biological-like hydroxyapatites. Chem. Mater. 18, 2181-2186 (2006).

36 Orefice, R., West, J., LaTorre, G., Hench, L. \& Brennan, A. Effect of long-term in vitro testing on the properties of bioactive glass-polysulfone composites. Biomacromolecules 11, 657-665 (2010).

37 Miyazaki, T., Imamura, M., Ishida, E., Ashizuka, M. \& Ohtsuki, C. Apatite formation abilities and mechanical properties of hydroxyethylmethacrylate-based organicinorganic hybrids incorporated with sulfonic groups and calcium ions. J. Mater. Sci. Mater. Med. 20, 157-161 (2009).

38 Isama, K. \& Tsuchiya, T. Enhancing effect of poly(L-lactide) on the differentiation of mouse osteoblast-like MC3T3-E1 cells. Biomaterials 24, 3303-3309 (2003).

Supplementary Information accompanies the paper on Polymer Journal website (http://www.nature.com/pj) 